\title{
ARTICLE
}

\section{Understanding community care law in England and Wales}

\author{
Danny Allen
}

\begin{abstract}
Danny Allen is a consultant adult psychiatrist for Oxfordshire and Buckinghamshire Mental Health NHS Foundation Trust. He works in an assertive outreach team and in a community acute service (an acute day hospital combined with a crisis and home treatment team). In 2005 he was awarded a Master of Laws (LLM) in Mental Health Law from Northumbria University.

Correspondence Dr Danny Allen, Oxfordshire and Buckinghamshire Mental Health NHS Foundation

Trust, Harlow House, Harlow Road, High Wycombe HP13 6AA, UK.

Email: danny.allen@obmh.nhs.uk
\end{abstract}

\begin{abstract}
SUMMARY
Although psychiatrists in England and Wales are generally familiar with the Mental Health Act 1983 and the Mental Capacity Act 2005, there is a body of law that is available to assist patients in the community with which they are generally less familiar. There are two main reasons for this. The first is that it is a rather confused amalgam of different statutes and case law affecting each other in ways that are less than clear. The other is that the care programme approach (CPA) was meant to cut through all this and make care provision straightforward. In fact, the latter has never been the case and community care law has always sat uneasily alongside the CPA, but in October 2008 the CPA was withdrawn from some patients with mental health problems. This article explains what is meant by community care law and how psychiatrists can use it to help their patients.

DECLARATION OF INTEREST

None.
\end{abstract}

Until recently, mental health professionals were encouraged to believe that the care programme approach (CPA) was the lynchpin of mental health services in the UK. However, a national review of the CPA led the Department of Health to conclude that it 'has often led to more attention being paid to the system (with ensuing needless bureaucracy) rather than a focus on good professional care' (Department of Health 2008a: p. 11). Thus, in October 2008, the soubriquet of the CPA was removed from all but individuals with a wide range of needs from a number of services, or who are at most risk' (Department of Health 2008a: p. 2).

Government policy has been to combine the CPA with social care assessments based on need under Section 47 of the National Health Service and Community Care Act 1990. The CPA, being based on a series of government circulars, can be (and now has partially been) withdrawn at the whim of a minister, whereas Section 47 needs assessments are based on statute law and everyone is eligible to be assessed. It therefore behoves mental health professionals to understand exactly what community care law consists of and how it can be used.

\section{History}

The CPA was introduced in England, Wales and Scotland the year after the National Health Service and Community Care Act 1990. Whereas the former is the creation of a government circular (Department of Health 1990a), the latter is an Act of Parliament, which applies to all people, not just those with mental health problems. The degree of overlap between the two is remarkable. Section 47 of the Act (which applies only to England and Wales), when read with all of the guidance associated with it, provides all the same services as the CPA, such as the assessment of health need, risk assessment, care planning and review, but on a statutory basis.

As long ago as 1996 the government stated that duplication of social care assessments for the CPA and care management can and should be avoided (Department of Health 1996a). In later years attempts have been made to integrate the two but in many parts of the UK this has not been achieved. The report of an inspection into CPA management (Department of Health 1999a) noted instances in which Social Services required the completion of both community care assessment forms and CPA forms.

A number of court cases have shown that councils have clear duties to provide some of the services that matter most to psychiatric patients - this will be discussed further below. In 2004, in an important legal case $(R$ (on the application of $H P$ and $K P$ ) v. London Borough of Islington [2004]), the judge dismissed as irrelevant a CPA assessment that had been done on the patient, instead instructing the local authority to complete a Section 47 needs assessment. The CPA plan had stated that services were not going to be provided, ostensibly because the current severity of the illness did not merit it; looked at in terms of the patient's vulnerability, a Section 47 needs assessment would almost certainly have concluded that he needed rehousing, as well as other services. Since October 2008 such a person might not even be eligible to take part in the CPA process. 


\section{What is community care law?}

The Mental Health Act 1983 affects only a minority of a psychiatrist's patients, since most are treated informally. Community care law (Box 1) potentially applies to every psychiatric patient, although unfortunately it is a hotchpotch of conflicting statutes (Clements 2004).

The power to provide welfare services under Section 29 of the National Assistance Act 1948 is not mandatory. However, Section 2(1) of the Chronically Sick and Disabled Persons Act 1970 converts this power into a duty with regard to people with a disability, including those with a mental illness.

The key to accessing all the provisions of community care law is the Section 47 needs assessment, which, when properly performed, opens the door to all of the statutory rights that patients have. In contrast, making the same statement of need on a CPA form provides no legal power to make it happen.

\section{How does this apply to NHS trusts?}

These days most National Health Service (NHS) mental health trusts have a formal partnership agreement with Social Services under Section 75 of the Health Act 2006. This means that they have a shared responsibility to carry out these assessments. Some have integrated these assessments into the CPA. Often though, the Section 47 assessments are seen as mere 'add ons' and often only materialise when it is decided that a client should attend a service that requires a 'care service order'.

This ad hoc approach to needs assessments means huge opportunities are missed for looking closely at peoples' needs and addressing them in individually tailored ways. Additionally, Section 47 needs assessments can be used as a management tool to guide the design of new services that meet the needs of discrete groups of people.

\section{What responsibilities do psychiatrists have?}

With regard to people who have been detained under the Mental Health Act 2007, case law ( $R$ (on the application of Munjaz) v. Ashworth Hospital Authority (now Mersey Care National Health Service Trust) [2005]) indicates that the code of practice (Department of Health 1999b: para. 27.4) should be followed unless there is a cogent reason for departing from it. National Health Service managers and directors of Social Services are enjoined by the code of practice to ensure that all staff are aware of the CPA and related provisions.
BOX 1 Essential components of community care law for England and Wales
- Part III of the National Assistance Act 1948 gives local authorities duties to provide residential accommodation and the power to provide welfare services to people who are over 18 and have a mental illness (among others). Its associated circular (Department of Health 1993) essentially converts the powers in the Act into duties with regard to certain categories of people, including those with mental illness

- Section 45 (as amended) of the Health Services and Public Health Act 1968 deals by the National Assistance Act 1948 with powers (although not duties) to provide various services for them mainly with the elderly, filling the gaps left
- Section 3(1)(e) of the National Health Service Act 2006 allows the National Health Service to provide the domiciliary and community needs of people who have a mental disorder of any description (including drug and alcohol problems). This is essentially the law that covers the basic work of non-hospital psychiatric services but it is vague in terms of what must actually be done for any individual

- Section 117 of the Mental Health Act 2007 provides aftercare for people who have been detained under Sections 3, 37, 47 or 48 of the Act (see 'Who pays')
When one looks into what these 'related provisions' are, one is directed to the document Building Bridges (Department of Health 1996a) referred to above, a main plank of which is that social care assessments should be integrated into the CPA.

The 'responsible clinician' has a duty to ensure, in consultation with the other professionals concerned, that the patient's needs for health and social care are fully assessed and that the care plan addresses these needs (Department of Health 1999b: para. 27.5). Since the mechanism for assessing social care needs is governed by Section 47 needs assessments, it is the responsibility of psychiatrists to ensure that this is done for all patients.

\section{How does it work?}

The exact way in which assessments are organised varies between different trusts, but ultimately Section 47 needs assessments are the responsibility of local authorities (Social Services). As mentioned above, however, Section 75 of the Health Act 2006 lets Social Services agree a relationship with the NHS allowing others to do this. Nevertheless, "up and down the country local authorities do still make short-term stop-gap decisions completely bypassing Section 47 needs assessments' ( $R$ (on the application of Tucker) v. Sutton London Borough Council [1998]).

Although local authorities are not obliged to fully assess frivolous claims, any request by a mental health worker would have to be taken seriously. Case law ( $R$ (on the application of Tucker) v. Sutton London Borough Council [1998]) suggests 
that failing to make a service provision decision or a proper care plan is not acceptable. Once a needs assessment has detailed what is required, this should be provided, although the time taken will depend on the circumstances. Unfortunately, the problem often seen in practice is that the assessment is not carried out properly or at all.

The results of the assessment should be set out as a care plan (Department of Health 1990b) and in many trusts this has now been formally combined in terms of the paperwork they use.

\section{What is 'Fair Access to Care Services' and why is it important?}

Since 1997 it has been established by case law ( $R$ (on the application of Barry) v. (1) Gloucestershire County Council and (2) Secretary of State for Health [1997]) that council resources (from council taxpayers' money) may be taken into account only when drawing up eligibility criteria; once eligible needs are identified, local authorities are under a duty to provide those services. It was to codify this difficult situation in England that the government produced its guidance on eligibility criteria for adult social care: 'Fair Access to Care Services' (also known as Fair Access or FACS) Department of Health 2002), which was supposed to have been implemented by 7 April 2003 but took much longer.

At the heart of the guidance is the principle that councils should operate just one eligibility decision for adults seeking social care support, that is: 'Should this person be helped or not?' This decision should be made following assessment of an individual's presenting needs. The main effect is to define eligibility for services using descriptions of vulnerability and risk rather than diagnostic or legal labels - the very issue over which the authorities in the case of HP and KP ( $R$ (on the application of HP and KP) v. London Borough of Islington [2004]), mentioned above, got themselves into hot water.

The framework within the Fair Access guidance is fairly prescriptive and is divided into four bands: critical, substantial, moderate and low, with each band broadly defined. On the basis of these eligibility criteria local authorities set a threshold below which they will not provide services - usually in the lower two bands.

The Fair Access guidance also reinforces the principle that when someone is deemed to have eligible needs, the local authority must develop a care plan that should include a note of needs and risks, preferred outcomes, contingency plans, details of services to be provided, contributions of carers and a review date, which, of course, means that the whole concept fits in with the CPA. With Fair Access, the greatest need in the hierarchy dictates the overall need band. And without Fair Access, people are not eligible to have direct payments (see below), meaning that their choices are curtailed.

\section{Case study 1: Angela}

Angela has a long history of schizophrenia; she has a flat but cannot live independently. She was desperately unhappy in a group home and kept refusing her depot medication. She loves gardening but cannot afford to buy plants and tools for the garden at her flat. Care programme approach plans have always mentioned her lack of appropriate housing and inability to do gardening as unmet needs.

A Section 47 needs assessment is done. It identifies that she could continue to live in her flat if she has someone with her for 4 hours a day to help with activities of daily living. Her need for this is classed as 'substantial'. She is also identified as needing gardening tools and plants. She has no savings so all of her services are fully funded. A carer from an independent sector agency is brought in for 6 days a week (on the 7th she visits her sister).

An application is made for direct payments and she is able to buy gardening tools and plants with the help of her carer. Angela is much more content living in her own flat. Her small garden is her pride and joy and she loves showing it to her community psychiatric nurse, who visits her fortnightly to give her depot as per the health part of the CPA plan.

\section{What is meant by need?}

There is really no limit to what is meant by the word 'need', and no restriction on the type of services that can be provided (Clements 2004). The principle is that the healthcare professionals involved will distinguish between needs and wants. Clearly, many people will want things that they need, but sometimes patients are not aware of many of their needs. Although one clearly cannot defend the idea that someone 'needs' a Rolls-Royce, they may very well have a need for transport to enable them to carry out an activity with some therapeutic or social value.

The guidance suggests that the sorts of services that may be provided include appropriate daytime activities, accommodation, treatment, personal and practical support, 24-hour emergency cover, and assistance with welfare rights and financial advice, as well as support for informal carers (Department of Health 1996b).

A key legal case has established that psychological needs may properly be included in a needs assessment ( $R$ (on the application of $M$ ) $v$. Avon County Council [1994]), meaning that living near relatives, for example, can be construed as a need. In practice, it would be important that the psychiatrist or psychologist caring for the 
patient clarifies with the social worker doing the assessment whether this is actually a need rather than just an understandable wish.

\section{Who pays?}

Unlike NHS treatment, all Social Services have to be charged for, but charging levels are set by the local authority, not the government, and are subject to means testing. Thus, the majority of seriously ill patients will not have to pay anything.

If a patient has been detained under Sections 3, 37, 47 or 48 of the Mental Health Act 1983 in the past and is still being looked after by specialist psychiatric services, the local authority of the patient's place of origin and the health authority in their current place of residence share a duty under Section 117 to provide aftercare services, including social care ( $R$ (on the application of Fox) v. Ealing District Health Authority [1993]). Furthermore, they have the power to put these services into motion before discharge ( $R$ (on the application of $K) v$. Camden and Islington Health Authority [2001]) and, following a key legal decision, it is unlawful to charge for these services ( $R$ (on the application of Stennett and others) V. Manchester City Council [2002]).

\section{Direct payments and individual budgets}

The government introduced the concept of direct payment, in line with its pursuit of patient choice. If someone is assessed as needing, for example, transport, care or even requisites for a leisure pursuit, then, provided that this has been deemed a need (using a Section 47 needs assessment incorporating the Fair Access criteria) and the criteria below are met, Social Services may give them the money to pay for it. The person has to be willing to have the service and, if required, an advocate can assist them, as a special bank account has to be set up for this purpose. It is especially good for leisure activities, 'befriending', laundry or other practical needs. It also opens up opportunities, including paying friends or relatives to provide transport or care where appropriate.

In 2008 the Department of Health funded a pilot of individual budgets that 'can enable people to use resources to design the type of support that works for them in meeting outcomes' (Department of Health 2008a: p. 19). Within a few years all local authorities will have to implement a system for the provision of individual budgets/selfdirected care for all of their clients (Department of Health 2008b). This means that people will be able to choose how to spend their social care allocation by a form of 'virtual payment' based on local authority credits.

\section{Housing}

It is not unusual for patients to wait in hospital for many months while appropriate accommodation is found for them. Much management effort often goes into dealing with 'bed-blockers' and practitioners know that there is no readily available accommodation and feel impotent to change the situation.

Both by the original definition in the National Assistance Act 1948 and by dint of a change in the law (Housing (Homeless Persons) Act 1977), when looking into the accommodation needs of people with mental illnesses (or any disability) housing legislation must be explored first. In non-unitary authorities (counties in which a single housing authority covers the whole county, but each council has its own Social Services department), Section 47 of the National Health Service and Community Care Act 1990 gives the local authority (council) a duty to inform the housing authority if it appears to them that there may be a need for any 'housing functions'. Because the Housing Act 1996 puts the housing authority under an obligation to receive applications (and the application does not have to be in any particular form), such a notification would effectively amount to an application made on behalf of the assessed person. In practice this tends to happen regularly with no problems.

However, for a number of the patients that a psychiatrist sees, ordinary housing is not an option and this is where the provisions of part III of the National Assistance Act 1948 come in. This gives duties to provide residential accommodation for people over 18 who have a mental illness. Case law ( $R$ (on the application of Wahid) v. Tower Hamlets London Borough Council [2002]) has shown that it can no longer be assumed that a need for care and attention can only be properly met in an institutional setting. Local authority Social Services may provide supported accommodation in ordinary housing stock with appropriate care input. This clearly has the potential to spur on commissioners - but only if the Section 47 needs assessments are done and brought to their attention.

\section{Carers}

The Carers (Recognition and Services) Act 1995 states that carers must be involved in the assessment and care-planning process and are entitled to an assessment in their own right. In practice, many local authorities have separate teams to do these assessments but they need to be combined with the Section 47 needs assessments to come to sensible decisions that benefit both patient and carer. 


\begin{tabular}{|c|c|c|c|c|}
\hline \multicolumn{5}{|c|}{ MCO answers } \\
\hline 1 & 2 & 3 & 4 & 5 \\
\hline$a f$ & af & af & af & \\
\hline$b \mathrm{t}$ & $b f$ & $b f$ & $b t$ & \\
\hline$c f$ & $c f$ & $c f$ & $c f$ & \\
\hline$d f$ & $d t$ & $d f$ & $d f$ & \\
\hline ef & ef & et & ef & \\
\hline
\end{tabular}

\section{Case study 2: Jonathan}

Jonathan has been in various psychiatric institutions for 5 years. For 3 days a week he goes home to his mother who gives him his medication there. He is very vulnerable and needs someone with him to stop him wandering off and walking into traffic. Various staffed placements have been proposed but have always been rejected by his mother as being too far away for her to visit.

A Section 47 needs assessment is carried out. Jonathan's need for someone to be with him is identified, as is his psychological need to be near his mother (supported by a letter from his consultant psychiatrist). It is also identified that Jonathan has a need for companionship with other young people. Furthermore, it is identified that Jonathan has a need for a leisure activity - he has always wanted to go fishing but can neither afford it nor organise this himself. His need for housing is graded as 'critical'. As he has savings under the statutory limit all his services are paid for. His mother has a carer's assessment that identifies her need for transport to visit and collect Jonathan, as well as her need for twice-yearly respite.

\section{Fair Access to Care Services}

As a person with a mental illness you are legally classified as having a disability. This entitles you to have your needs automatically assessed by Social Services. Psychological needs may be included in a needs assessment. If, for whatever reason, you are not assessed in the way described below, you or your carer may ask Social Services to provide an assessment. You may also be able to assess some of your own needs and, if necessary, Social Services may be able to assist you with advocacy in this regard.

The assessment must follow a strict protocol and end up by classifying your needs as critical, substantial, medium or low. These are called the Fair Access to Care Services (Fair Access, or FACS) criteria and if you fall within a band that your Social Services funds they must either provide for these needs themselves or make sure they are provided for by another agency (such as a voluntary organisation). You may ask for the results of your assessment, which should be set out as a care plan. This could form part of your care programme approach (CPA) care plan.

Among other things, Social Services have the ability to provide or arrange accommodation. Once a needs assessment has decided what is required, the services should be made available, although you may be charged for this if you have income above the welfare benefits level.

If you have been detained under Sections 3, 37, 47 or 48 of the Mental Health Act 1983 in the past and are still being looked after by specialist psychiatric services, the local authority of the place in which you originally lived and the health authority in the area you now live in share a duty to provide you with aftercare services, including social care, which they have the power to put into motion before you are discharged; they are not allowed to charge you for these services. These services are also available to patients on Section 17 leave and must be continued until the health and local authorities are satisfied that they are no longer necessary. There is no restriction on the type of services that can be provided.

Carers must be involved in the assessment and care-planning process and have a right to a carer's assessment. Social Services guidance requires that carers are informed of this right and are given a leaflet. They have a right to be given the services that they are assessed as needing.

Jonathan is placed in a group home 7 miles away from his mother but she has twice-weekly taxis provided. In return, she continues to look after him for 3 days a week but when he is in the group home the local authority pays for a carer from a private agency to be with him during waking hours. An application is made for direct payments and he is able to join a fishing club with money given to him for this purpose and administered with the aid of an advocate from a local group. He visits the fishing club weekly with his carer and pays for transport out of his Disability Living Allowance. He and his carer go out most days - to the shops, for a walk or to the cinema. Twice a year his mother has a week off when a carer stays with him all week.

Jonathan is happy to take his oral medication with minimal prompting from either the carer or his mother and gladly sees his community mental health nurse, who visits monthly as per the health part of the CPA plan. Jonathan feels that the quality of his life has improved immeasurably.

\section{What does all this mean for everyday practice?}

It is notable that whenever a case has been brought to court the local authority has complied for that individual but, so far, this has fallen short of generating rulings that would require all local authorities to comply. The fact remains that patients are not going to get what the law entitles them to unless these statutory assessments are properly completed. However, the fact that selfassessments are now being encouraged under the personal budget developments mentioned above gives some hope that, despite the likely need for advocacy for many of patients, this may speed up access to assessment.

However, if psychiatrists are ignorant of these provisions, they cannot inform their patients or request that their social work colleagues carry out Section 47 needs assessments according to the Fair Access criteria. Psychiatrists can make patients aware of their rights by explaining them verbally or by providing appropriately pitched written information. An example of an information leaflet is shown in Fig. 1.

\section{Does the CPA still matter?}

Until recently the CPA was the government's only framework for providing mental health services. However, since October 2008 it has applied only to 'individuals with a wide range of needs from a number of services, or who are at most risk' (Department of Health 2008a: p. 12), which more or less equates to the original concept of enhanced CPA. There is therefore a real risk that many patients whose needs are simple but significant will be excluded from the CPA in future. However, in principle Section 47 needs assessments remain open to all. 
'Because CPA is a process and not a measure of eligibility' (Department of Health 2008a: p. 13) psychiatrists should ensure that an assessment of risk, health and social care (compliant with a Section 47 needs assessment) is done for any patient who appears to have an unmet need.

\section{References}

Clements L (2004) Community Care and the Law. Legal Action Group.

Department of Health (1990a) The Care Programme Approach for People with a Mental IIIness Referred to the Specialist Psychiatric Services (Health Circular HC(90)23; Local Authority Social Services Letter LASSL(90)11). Department of Health.

Department of Health (1990b) Caring for People. Community Care in the Next Decade and Beyond. Policy Guidance. (TSO) The Stationery Office.

Department of Health (1993) Approvals and Directions for Arrangements from 1 April 1993 Made Under Schedule 8 to the National Health Service Act 1977 and Sections 21 and 29 of the National Assistance Act 1948 (Local Authority Circular LAC(93)10). Department of Health.

Department of Health (1996a) Building Bridges: Arrangements for InterAgency Working for the Care and Protection of Severely Mentally III People (HSG (95)56). Department of Health.

Department of Health (1996b) Guidance on Mental Health (Patients in the Community) Act 1995 (accompanying Local Authority Circular LAC(96)8 and Health Service Guidelines HSG(96)11). Department of Health.

Department of Health (2002) Fair Access to Care Services. Guidance on Eligibility Criteria for Adult Social Care (Local Authority Circular $L A C(02) 13)$. Department of Health.
Department of Health (2008a) Refocusing the Care Programme Approach: Policy and Positive Practice Guidance. Department of Health.

Department of Health (2008b) Transforming Social Care (Local Authority Circular LAC (DH)(2008)1). Department of Health.

Department of Health, Social Services Inspectorate (1999a) Still Building Bridges. The Report of a National Inspection of Arrangements for the Integration of the Care Programme Approach with Care Management: para 1.28. Department of Health and Social Services Inspectorate.

Department of Health, Welsh Office (1999b) Code of Practice to the Mental Health Act 1983. (TSO) The Stationery Office.

$R$ (on the application of Barry) v. (1) Gloucestershire County Council and (2) Secretary of State for Health [1997] 1 CCLR 40.

$R$ (on the application of Fox) v. Ealing District Health Authority [1993] 1 WLR 373.

$R$ (on the application of HP and KP) v. London Borough of Islington [2004] EWHC 7 Admin.

$R$ (on the application of K) v. Camden and Islington Health Authority[2001] EWCA Civ 240.

$R$ (on the application of M) v. Avon County Council [1994] 2 FLR 1006.

$R$ (on the application of Munjaz) v. Ashworth Hospital Authority (now Mersey Care National Health Service Trust) [2005] UKHL 58

$R$ (on the application of Stennett and others) v. Manchester City Council [2002] UKHL 34

$R$ (on the application of Tucker) v. Sutton London Borough Council [1998] 1 CCLR 251.

$R$ (on the application of Wahid) v. Tower Hamlets London Borough Council [2002] WL 237056

\section{MCOs}

1 Section 47 needs assessments are based on:

a Mental Health Act 2007 status

b vulnerability

c diagnosis

d severity of the condition

e CPA level.

2 The desirability of avoiding the duplication of social care assessments is mentioned in:

a The National Health Service and Community Care Act 1990

b $R$ (on the application of Munjaz) v. Ashworth Hospital Authority (now Mersey Care National Health Service Trust)[2005]

c $R$ (on the application of HP and KP) $v$. London Borough of Islington [2004] d Building Bridges (Department of Health 1996a)

e the Mental Health Act 2007.

3 Section 47 needs assessments have had to follow the Fair Access criteria since:

a November 2004

b March 1990

c October 2001

d April 2000

e April 2003

\section{A requirement for eligibility for direct} payments is:

a a friend willing to provide the service

b a needs assessment done in accordance with

Fair Access criteria

c a need approved by Social Services 